\title{
A coalescence of two syndromes in a girl with terminal deletion and inverted duplication of chromosome 5
}

\author{
Danijela Krgovic ${ }^{1}$, Ana Blatnik', Ante Burmas², Andreja Zagorac ${ }^{1}$ and Nadja Kokalj Vokac ${ }^{1,3^{*}}$
}

\begin{abstract}
Background: Rearrangements involving chromosome $5 p$ often result in two syndromes, Cri-du-chat (CdC) and Trisomy 5p, caused by a deletion and duplication, respectively. The $5 p 15.2$ has been defined as a critical region for $\mathrm{CdC}$ syndrome; however, genotype-phenotype studies allowed isolation of particular characteristics such as speech delay, cat-like cry and mental retardation, caused by distinct deletions of $5 \mathrm{p}$. A varied clinical outcome was also observed in patients with Trisomy 5p. Duplications of 5p10-5p13.1 manifest themselves in a more severe phenotype, while trisomy of regions distal to $5 \mathrm{p} 13$ mainly causes mild and indistinct features. Combinations of a terminal deletion and inverted duplication of $5 p$ are infrequent in literature. Consequences of these chromosomal rearrangements differ, depending on size of deletion and duplication in particular cases, although authors mainly describe the deletion as the cause of the observed clinical picture.

Case presentation: Here we present a 5-month-old Slovenian girl, with de novo terminal deletion and inverted duplication of chromosome $5 \mathrm{p}$. Our patient presents features of both $\mathrm{CdC}$ and Trisomy 5. The most prominent features observed in our patient are a cat-like cry and severe malformations of the right ear.

Conclusion: The cat-like cry, characteristic of CdC syndrome, is noted in our patient despite the fact that the deletion is not fully consistent with previously defined cat-like cry critical region in this syndrome. Features like dolichocephaly, macrocephaly and ear malformations, associated with duplication of the critical region of Trisomy $5 p$, are also present, although this region has not been rearranged in our case. Therefore, the true meaning of the described chromosomal rearrangements is discussed.
\end{abstract}

Keywords: Deletion with inverted duplication of 5p, Cri-du-chat syndrome, Trisomy 5p, Cat-like cry, Ear agenesis

\section{Background}

Chromosomal rearrangements involving the short arm of chromosome 5 often result in two well-known syndromes, Cri-du-chat $(\mathrm{CdC})$ and Trisomy $5 \mathrm{p}$, caused by a deletion and duplication, respectively. $\mathrm{CdC}$ is one of the recognizable contiguous gene disorders, therefore much has been done in terms of genotype-phenotype correlations [1]. A cat-like cry is considered to be a hallmark observed in $\mathrm{CdC}$ patients, although clinical manifestations generally depend on the $5 p$ segment involved in the deletion $[1,2]$.

\footnotetext{
*Correspondence: nadja.kokalj-vokac@ukc-mb.si

'Laboratory of Medical Genetics, University Clinical Centre Maribor,

Ljubljanska Street 5, 2000 Maribor, Slovenia

${ }^{3}$ Faculty of Medicine, University of Maribor, Slomškov trg 15, 2000 Maribor, Slovenia

Full list of author information is available at the end of the article
}

A distinct facial appearance with mental retardation has been delineated in these patients, associated with a deletion of $5 \mathrm{p} 15.2$. This region was therefore postulated to be the critical region of the syndrome [3,4]. Introducing more advanced techniques in diagnostics has allowed further determination and isolation of particular characteristics such as speech delay, cat-like cry, mental retardation, and facial dysmorphism, caused by distinct deletions of $5 p$ in patients lacking the full clinical $\mathrm{CdC}$ spectrum $[5,6]$.

A varied clinical manifestation was also observed in patients with Trisomy 5p, depending on the position of the duplication $[7,8]$. Duplications involving complete $5 \mathrm{p}$ or a small segment between $5 \mathrm{p} 10-5 \mathrm{p} 13.1$ usually manifest in a more severe phenotype; thus, this region was proposed to be the critical region for Trisomy $5 p$ [9-11]. Meanwhile, trisomy of regions distal to 5 p13 mainly

\section{Biomed Central}


causes mild and indistinct features [12]. A combination of terminal deletion and inverted duplication of $5 p$ is infrequent in literature. To the best of our knowledge, only six patients have been reported so far [8,13-17]. Consequences of these uncommon chromosomal rearrangements differ, depending on the size of the deletion and duplication in each particular case. This is shown in variable clinical pictures observed, although authors mainly describe deletion as causative for the clinical outcome $[8,13,16,17]$.

Here we present a new patient with a terminal deletion and inverted duplication of chromosome 5p. Our patient presents a cat-like cry, characteristic of $\mathrm{CdC}$ syndrome. Features like dolichocephaly, macrocephaly and ear malformations, observed in Trisomy $5 \mathrm{p}$, are also present. By comparing our patient to those previously reported, we aim to clarify the potential role of the deletion and duplication in this type of chromosomal rearrangement.

\section{Case presentation}

\section{Clinical report}

Currently 5-month-old girl was born by caesarean section at 32 weeks' gestation due to preterm premature rupture of membranes to a 31-year old, gravida 3 para 2 mother. The pregnancy was uneventful with the exception of an episode of minor bleeding in the first trimester. The parents are healthy non-consanguineous. Two months after the delivery, the patient's mother was diagnosed with choriocarcinoma and underwent chemotherapy and surgical treatment. The family history was otherwise unremarkable. The newborn's birth length was $36 \mathrm{~cm}$, her weight $1440 \mathrm{~g}$, head circumference $28 \mathrm{~cm}$. Her Apgar score was 5 at 1 minute and 6 at 5 minutes after birth due to respiratory distress and received ventilatory support for four days. Feeding became increasingly difficult at the age of two weeks, mostly due to uncoordinated movements of the supralaryngeal structures and sub sequential aspiration. The difficulties seemed to be resolving as she reached the age of two months but have reappeared since, requiring a gastrostomy tube placement. Immediately after birth, she was diagnosed with right-sided anotia with two preauricular skin tags. An MRI showed atresia of the right ear canal but normal middle and inner ear structures. Hearing tests performed on the left ear were normal. In addition, she had partial bilateral choanal atresia. An echocardiogram revealed a haemodynamically insignificant ventricular septum defect and a patent ductus arteriosus. Abdominal ultrasound examination was unremarkable, although both kidneys seemed to be smaller than expected. In the neonatal period a neurological examination revealed central hypotonia, which was less evident when she was re-examined at the adjusted age of three months. Signs of a slight developmental delay were also noted. Her electroencephalogram was normal, but a brain MRI revealed a dilated right lateral ventricle with possible periventricular heterotopia and somewhat smaller hippocampal regions. At the adjusted age of three months our patient weight was $5000 \mathrm{~g}$, length $59 \mathrm{~cm}$, head circumference $42.5 \mathrm{~cm}$. Dysmorphic facial features were more prominent than in the neonatal period and included dolichocephaly with relative macrocephaly, right ear agenesis with preauricular ear tags, hypertelorism and microretrognathia. When she was re-examined at the adjusted age of five months, additional features were noted - convergent strabismus, long eyelashes and widely spaced nipples. Both her height and weight were at the 5th percentile for her adjusted age (Figure 1). A characteristic high-pitched cry first described directly after birth was still present.

\section{Methods \\ Array-CGH analysis}

Array-CGH was performed on DNA extracted from peripheral blood leukocytes of the patient and her parents using the BlueGnome CytoChip ISCA $8 \times 60 \mathrm{~K}$ platform (BlueGnome Limited, Cambridge, United Kingdom). The assay was performed according to the manufacturer's instructions (CytoChip Oligo v1.2, 1st February 2011, BlueGnome, Cambridge, UK). The obtained data were analysed using the Blue Fuse Multi v3.1 software tool (BlueGnome, Cambridge, UK).

\section{Chromosome analysis}

Chromosome analysis was performed on metaphase chromosomes from peripheral blood lymphocytes on the patient and her parents. Chromosomes were harvested according to standard cytogenetic methods and analysed by G-bands.

\section{FISH analysis}

The deletion and duplication on chromosome $5 \mathrm{p}$ were verified by fluorescent in situ hybridisation (FISH) carried out on metaphase spreads using the following BlueFISH BAC probes: RP11-73G8 orange (5p15.32), RP11-433G24 green (5p15.31), RP11-203I22 green (5p15.31, encompassing FLJ25076 gene), and RP11-96P21 orange (5p15.2) (BlueGnome, Cambridge, UK), according to the manufacturer's instructions (BlueFish" ${ }^{\text {mix }}$ protocol v4, July 9th 2009, BlueGnome, Cambridge, UK).

\section{Results}

\section{Array-CGH analysis}

The array-CGH analysis indicated a smaller terminal deletion $(6.3 \mathrm{Mb})$ and much larger interstitial duplication $(29.6 \mathrm{Mb})$ on the short arm of chromosome 5 . The positions of the rearrangements were determined to be $\operatorname{arr}[\mathrm{hg} 19] 5 \mathrm{p} 15.33 \mathrm{p} 15.31(22,179-6,303,297) \times 1$ dn,5p15.31p13.2(6,414,458-36,094,217) × 3 dn (Figure 2a). 


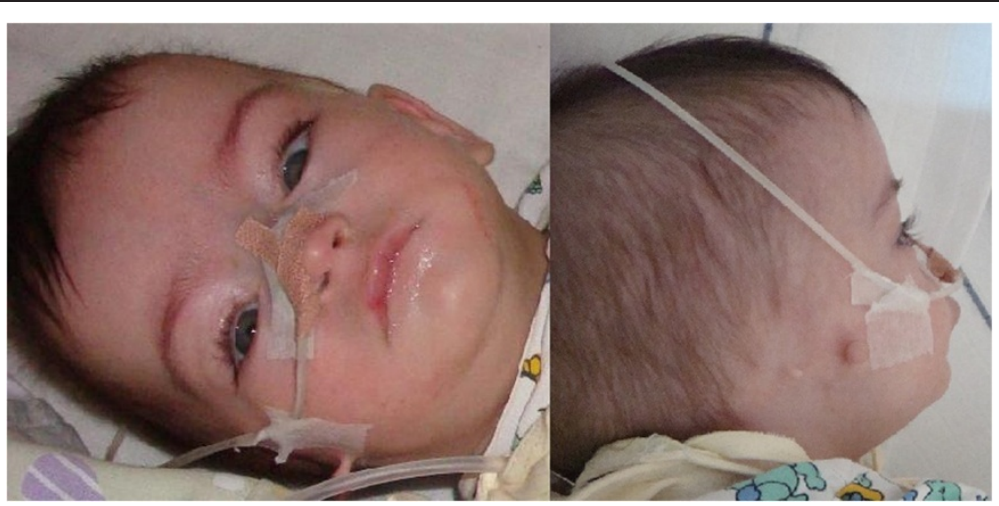

Figure 1 Facial appearance of the patient at the adjusted age of 5 months. Note dolichocephaly, relative macrocephaly, right ear agenesis with preauricular ear tags, hypertelorism and microretrognathia.

\section{Chromosome analysis}

The chromosomal rearrangements detected by array-CGH were confirmed by karyotyping as 46,XX,der(5) (Figure 2b). The proband's parents had normal array-CGH profiles and karyotypes (data not shown). FISH analysis was performed in order to establish the precise type of rearrangements.

\section{FISH analysis}

A deletion of the 5p15.31-5pter was confirmed using a combination of the RP11-73G8 orange (5p15.32) probe in the deleted region and the RP11-203I22 green (5p15.31, encompassing FLJ25076 gene) probe in the duplicated region. Absence of the orange signal on the rearranged chromosome 5 represents a deletion of region $5 \mathrm{p} 15.32$. Both probes were evident on the normal chromosome 5 (Figure 3a). The RP11-203I22 (5p15.31) probe also covers the whole FLJ25076 gene. From the brighter and larger green signal observed on the rearranged chromosome 5, we concluded that the gene was duplicated in our case (Figure 3a). The inverted duplication was confirmed using RP11-433G24 green (5p15.31) probe, which lies distal to the breakpoint of two described rearrangements

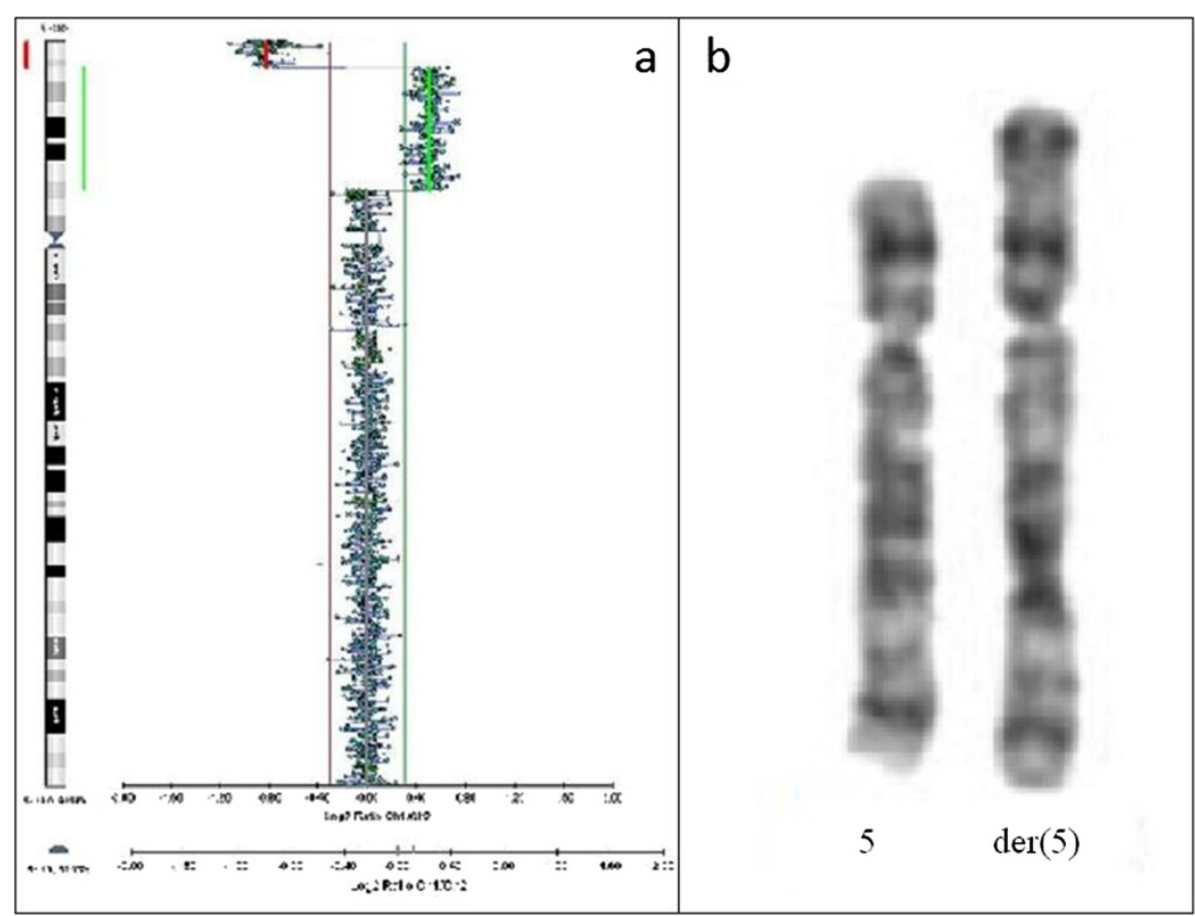

Figure 2 The result of molecular and standard karyotyping of the patient. (a) An array-CGH analysis showing a terminal deletion and duplication of $5 p$. The breakpoints of rearrangements were determined to be $\operatorname{arr}[\mathrm{hg} 19] 5 \mathrm{p} 15.33 \mathrm{p} 15.31(22,179-6,303,297) \times 1 \mathrm{dn}, 5 \mathrm{p} 15.31 \mathrm{p} 13.2$ $(6,414,458-36,094,217) \times 3$ dn. (b) A normal and rearranged chromosome 5 after GTG banding. 


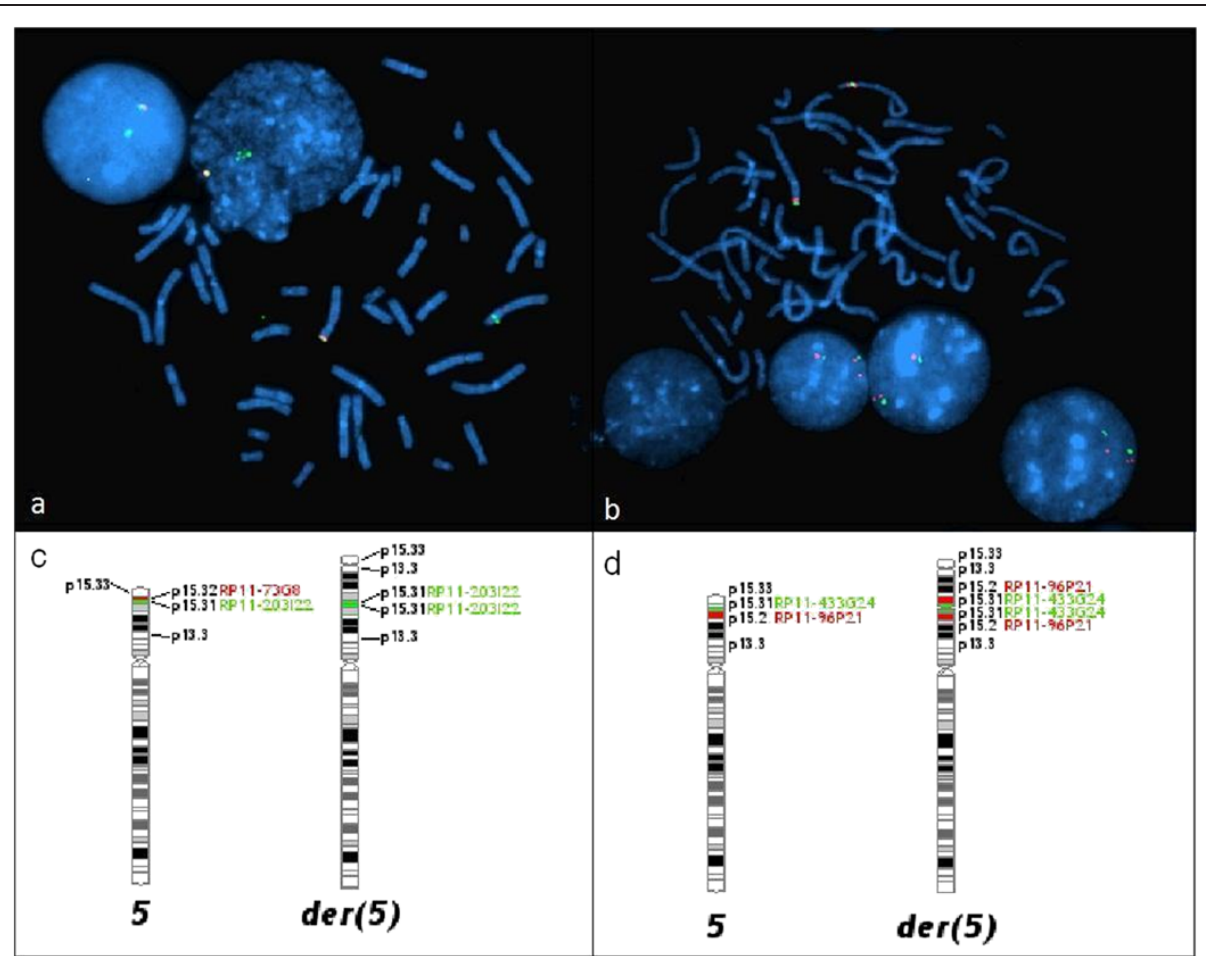

Figure 3 FISH analysis. (a) The deletion was verified using probe RP11-73G8 orange (5p15.32). A single orange signal was detected on the normal chromosome 5 and in the nucleus, whereas the signal was absent on the rearranged chromosome 5. Two green signals, one on each chromosome 5 , represent the RP11-203122 (5p15.31) probe, encompassing the FL25076 gene. The brighter green signal on the rearranged chromosome 5 indicates that this gene is duplicated. (b) The type of duplication was determined by RP11-433G24 green (5p15.31) and RP11-96P21 orange (5p15.2) probes. Two orange signals (RP11-96P21) on each side of the green signal (RP11- 433G24) on the rearranged chromosome 5 indicated that the duplication was inverted. (c) An idiogram of the normal and rearranged chromosome 5 with probe positions used in Figure 3a is presented. (d) An idiogram of the normal and rearranged chromosome 5 with probe positions used in Figure $3 \mathrm{~b}$ is presented.

and RP11-96P21 orange (5p15.2) probe, which lies within the critical region of $\mathrm{CdC}$ syndrome. Two orange signals (RP11-96P21) on either side of a green signal (RP11433G24) on the rearranged chromosome 5 represented an inverted duplication of the 5p13.2-5p15.31 (Figure 3b). According to all methods used, the proband's karyotype could be written as 46,XX,der(5).ish $\operatorname{der}(5) \operatorname{del}(5)(\mathrm{p} 15.31$ p15.33)inv dup(5)(p13.2p15.3)(RP11-73G8-,RP11-203I22++, RP11-96P21++,RP11-433G24+).arr[hg19] 5p15.31p13.2 $(6414458-36094217) \times 3$ dn,5p15.33p15.31(22179-6303 297) $\times 1 \mathrm{dn}$.

\section{Discussion}

Although array-CGH analysis has become a widely used method in diagnostics of children with developmental delays, intellectual disabilities and congenital anomalies, incidence of complex rearrangements involving chromosome $5 \mathrm{p}$ as described here is still very low. Vetro et al. [14] assumed that these rearrangements are underestimated due to the limitations of the standard cytogenetic techniques used, and methods like array-CGH will enable new cases to be discovered. Only three new cases have been reported since the Vetro et al. [14] study and six altogether $[8,13-17]$, reflecting the rarity of this phenomenon.

In 1999, Sreekantaiah et al. [8] described the first case of a terminal deletion with inverted duplication of $5 p$ in a 4-year-old girl with developmental delay and cat-like cry noted at birth. Minor dysmorphic features were also observed, but the subject lacked other characteristics of $\mathrm{CdC}$ syndrome. In subsequent years, five more cases have been reported, two postnatal and three prenatal. Wang et al. [13] reported a 6-year-old boy with speech and motor skill delay, without $\mathrm{CdC}$ features. Vetro et al. [14] presented a prenatal case with cystic hygroma and other congenital facial and body anomalies, including dolichocephalia, low-set ears with malformed helices, microretrognathia and others. A newborn with similar chromosomal rearrangements of $5 p$ was described by Vera-Carbonell et al. [15], presenting both features of $\mathrm{CdC}$ syndrome and Trisomy $5 \mathrm{p}$. The patient died at the age of three months due to a congenital heart defect. Recently, two more prenatal cases were described by Mosca et al. [16] and Izzo et al. [17]. The first presented a deformed skull, facial asymmetry, hypertelorism, exophthalmia, microretrognathia, long philtrum and large 
mouth, short nasal ridge, anteverted nostrils, bilateral rocker-bottom feet, and hypoplastic helix [16]. A patient from Izzo et al. [17] displayed only mild phenotypic abnormalities and facial dysmorphisms. Here we present a new case of de novo terminal deletion with an inverted duplication in a 5-month-old girl. Our patient presents features of both $\mathrm{CdC}$ and Trisomy 5 . The most prominent features observed in our patient are a cat-like cry and severe malformations of the right ear.

All above mentioned cases describe terminal deletions followed by inverted duplications of varied size. When comparing phenotypes, we see clear differences between patients, including our own (Table 1). The hypotonia, psychomotorical retardation or developmental delay, hypertelorism, microretrognathia, and low-set ears observed in our proband are characteristics shared by both $\mathrm{CdC}$ syndrome and Trisomy 5p $[1,18]$. The first two listed features and the cat-like cry, a hallmark of $\mathrm{CdC}$, are present in three out of four postnatal patients. Additionally, strabismus, feeding problems, and respiratory difficulties described in Trisomy $5 \mathrm{p}$ are present in two out of four live births. Hypertelorism was observed in three, microretrognathia and low-set ears in four out of seven patients. Dolichocephaly and macrocephaly, features involved in Trisomy 5p, are described in two and one patient, respectively. Specific features noted in our patient are right-sided anotia with atresia of the right ear and choanal atresia. Although ear malformations are present in Trisomy 5p [7], severe ear anomalies are not frequently reported. Minor ear malformations are observed in two other patients with a deletion and inverted duplication of $5 \mathrm{p}$. The preauricular skin tags seen in our patient and the patient described by Wang et al. [13] are occasionally described in $\mathrm{CdC}$ patients [1].

A genotype-phenotype correlation of $\mathrm{CdC}$ syndrome has been carried out in the past, in order to distinguish the critical genomic regions for the cat-like cry, distinct facial dysmorphism, microcephaly, and severe psychomotor delay and mental retardation, features most prominent in the first year of life in $\mathrm{CdC}$ patients [1]. Several of these studies mapped the critical regions to different positions on the $5 p$, leading to conflicting results $[2,3,19,20]$. Two distinct cat-like cry critical regions have been mapped, one to the proximal part of $5 \mathrm{p} 15.3[3,19,20]$ and one to the distal part of 5p15.2 [2]. The array-CGH analysis allowed more precise localization of the cat-like cry critical region between $6.0-7.5 \mathrm{Mb}$ on $5 \mathrm{p} 15.31$ [6]. The region was further narrowed in the study by Wu et al. [5], using quantitative PCR, to a $640 \mathrm{~kb}$ small region on 5p15.31, containing just three candidate genes FLJ25076, FLJ20303, and MGC5309. Among these three genes, gene FLJ25076 was proposed as a candidate gene. Namely, expression profiles determined by quantitative PCR showed that the FLJ25076 gene is locally expressed in thoracic and scalp tissue, whereas the other two genes are expressed uniformly in all tissues tested [5]. Interestingly, the genes proposed by this study are duplicated in our case. Duplication has been confirmed with both array$\mathrm{CGH}$ and FISH analysis (Figures $2 \mathrm{a}$ and $3 \mathrm{~b}$ ). We used the RP11-203I22 green (5p15.31) probe, specific to the FLJ25076 gene, most plausible of the proposed genes. Two green signals on chromosomes 5 confirmed the presence of this gene on both the normal and the rearranged chromosome 5. A bright green patch signal on the rearranged chromosome 5 and its position indicate that the FLJ25076 gene is duplicated in this chromosome (Figure 3a).

An almost $30 \mathrm{Mb}$ large duplication identified in our patient, which resides on 5p13.2-5p15.31, lies just outside the critical region $5 \mathrm{p} 10-5 \mathrm{p} 13.1$ postulated for Trisomy $5 \mathrm{p}$ syndrome $[9-11,15]$. However, vague boundaries were also reported in this syndrome, putting the critical region between 5p10-5p13.3 [21-23]. Nevertheless, it is generally accepted that duplications of regions located proximal to 5 p13 most likely have greater significance in the clinical severity in Trisomy $5 p$ than duplications involving regions distal to 5p13. Dolichocephaly, macrocephaly, microretrognathia, low-set dysplastic ears, congenital heart, and respiratory defects noted in our proband are only some of the features described in the Trisomy $5 p$ phenotype. Some of these features are also shared with features of $\mathrm{CdC}$. Low-set ears and microretrognathia are noted in most $\mathrm{CdC}$ patients, whereas cardiac anomalies and respiratory infections are not frequently reported [1]. Therefore, according to the phenotype described in patients with Trisomy 5p, we conclude that dolichocephaly and macrocephaly are features caused by the duplication determined in our proband. A right-sided anotia with atresia of the right ear is also consistent with dysplastic ears reported in $5 p$ duplication patients [21], although the described patients usually present dysplastic ears in terms of malformed helix and not severe ear malformation as found in our proband.

Intertwining phenotypic features of both $\mathrm{CdC}$ and Trisomy $5 p$ syndromes in patients with a terminal deletion with inverted duplication make it difficult to clearly distinguish the effect of the individual chromosomal rearrangements on the clinical outcome. Based on the position of the deletion, which in our case lies between 5p15.31-5pter, we deduce that the cat-like cry, a hallmark of $\mathrm{CdC}$ syndrome, originates from the above-mentioned deletion of the region. Where exactly the critical region is located remains uncertain. As mentioned above, the FLJ25076, FLJ20303, and MGC5309 genes postulated in the study by Wu et al. [5] are duplicated in our case, which is inconsistent with their findings. Interestingly, Wang et al. [13] reported a patient with a $6.9 \mathrm{Mb}$ terminal deletion followed by an inverted duplication, who did not present a cat-like cry at birth. 
Table $1 \mathrm{CdC}$ and Trisomy 5p features noted in patients with terminal deletion and inverted duplication of 5p

\begin{tabular}{|c|c|c|c|c|c|c|c|c|}
\hline & $\begin{array}{c}\text { Sreekantaiah et al. } \\
1999[8]\end{array}$ & $\begin{array}{l}\text { Wang et al. } \\
2008 \text { [13] }\end{array}$ & $\begin{array}{l}\text { Vetro et al. } \\
2008 \text { [14] }\end{array}$ & $\begin{array}{c}\text { Vera-Carbonell et al. } \\
2009[15]\end{array}$ & $\begin{array}{l}\text { Mosca et al. } \\
2011 \text { [16] }\end{array}$ & $\begin{array}{l}\text { Izzo et al. } \\
2012 \text { [17] }\end{array}$ & Our patient 2013 & \\
\hline Deletion & 5p15.33p15.3 & $5 p 15.33 p 15.31$ & $5 p 15.33 p 14.1$ & 5p15.33p14.2 & 5p15.33p15.3 & $5 p 15.33$ & $5 p 15.33 p 15.31$ & Deletion \\
\hline Size & $9.9 \mathrm{Mb}$ & $6.9 \mathrm{Mb}$ & $25 \mathrm{Mb}$ & $24.34 \mathrm{Mb}$ & $6.6 \mathrm{Mb}$ & $870 \mathrm{~kb}$ & $6.3 \mathrm{Mb}$ & Size \\
\hline Duplication/inversion & 5p15.3p14 & 5p15.31p14.3 & 5p14.1p11 & $\begin{array}{l}5 p 14.2 p 13.1 \text { with } \\
\text { duplication to } 5 \mathrm{p} 12\end{array}$ & $5 p 15.31$ & 5p15.33p13.1 & $5 p 15.31 p 13.2$ & Duplication/inversion \\
\hline Size & $10 \mathrm{Mb}$ & $13 \mathrm{Mb}$ & $20.3 \mathrm{Mb}$ & $20.72 \mathrm{Mb}$ & $2.3 \mathrm{Mb}$ & $40.5 \mathrm{Mb}$ & $29.7 \mathrm{Mb}$ & Size \\
\hline Heredity & De novo & De novo & De novo & De novo & De novo & de novo & De novo & Heredity \\
\hline Age of the patient & 4 years & 6 years & prenatal & Newborn & Prenatal & Prenatal & Newborn & Age of the patient \\
\hline Gender & $\mathrm{F}$ & M & M & $\mathrm{F}$ & M & & $\mathrm{F}$ & Gender \\
\hline Pregnancy/Birth & Normal & Premature & Termination & 39 weeks & Termination & Termination & Premature & Pregnancy/Birth \\
\hline Trisomy $5 p$ features & & & & & & & & Cri-du-chat features \\
\hline Head & & & & & & & & Head \\
\hline Dolichocephaly & & & + & & & & + & \\
\hline Macrocephaly & & & & & & & + & \\
\hline Hypertelorism & & & hypo- & + & + & & + & Hypertelorism \\
\hline Microretrognathia & & & + & + & + & & + & Microretrognathia \\
\hline Ears & & & & & & & & Ears \\
\hline \multirow[t]{2}{*}{ Low-set ears } & & & + & + & & + & + & Low-set ears \\
\hline & & + & & & & & + & Preauricular skin tags \\
\hline Dysplastic ears & & & + & & + (left) & & + (left) & \\
\hline Nose & & & & & & & & Nose \\
\hline Broad nasal bridge & & & & + & & & + & Broad nasal bridge \\
\hline Eyes & & & & & & & & Eyes \\
\hline Epicanthal folds & & & & & & & + & Epicanthal folds \\
\hline Strabismus & + & & & & & & + & \\
\hline Heart & & & & & & & & Heart \\
\hline CHD & & & + & + & & & + & $C H D$ \\
\hline Neurological & & & & & & & & Neurological \\
\hline Developmental delay & + & + & & & & & + & $\begin{array}{l}\text { Developmental } \\
\text { delay }\end{array}$ \\
\hline Hypotonia & & + & & + & & & + & Hypotonia \\
\hline
\end{tabular}


Table $1 \mathrm{CdC}$ and Trisomy $5 p$ features noted in patients with terminal deletion and inverted duplication of $5 p$ (Continued)

Cry 
They suggested that the critical region for the cat-like cry resides within the $0.6 \mathrm{Mb}$ region between $6.9-7.5 \mathrm{Mb}$, which also conflicts with our findings. According to the deletion described in our proband and the cat-like cry region (deletion between $6.0-7.5 \mathrm{Mb}$ ) proposed by Zhang et al. [6] we can assume that the genes responsible for this feature are located in the region between 6.0-6.3 Mb on $5 \mathrm{p} 15.31$. Unfortunately, positioning of the cat-like cry critical region and isolation of the candidate genes is not feasible at this moment in time, suggesting a higher need for more precise genotype-phenotype studies. Nevertheless, the uncoordinated movements of the supralaryngeal structures noted in our proband are, apart from feeding difficulties, probably also connected to the cat-like cry. Our patient's deletion also encompasses a critical region for speech delay in $\mathrm{CdC}$ syndrome associated with 3.2-6.4 Mb sized rearrangement of the 5p15.3 band $[2,6]$. Currently, no information regarding this feature can be provided for our patient, but it is possible that she will have difficulties with speech in the future.

In our case, the impact of the duplication should be stressed. Contrary to the earlier publications of terminal deletions with inverted duplications, where minor impact of duplication has been suggested $[8,13,16,17]$, the duplication in our case seems to be crucial for the observed clinical picture. Some features, such as macrocephaly, dolichocephaly, and dysplastic ears may not be induced by the duplication of a critical region of Trisomy $5 \mathrm{p}$, and are a result of the duplication of genes positioned distal to $5 \mathrm{p} 13$. It is also possible that the Trisomy $5 \mathrm{p}$ critical region does not extend to the whole $5 \mathrm{p} 13$ band as Izzo et al. [17] proposed previously. Interestingly, although the duplication reported in their case exceeds the size of the duplication reported in this paper, a milder phenotype was observed in their patient. This only confirms the complexity of the Trisomy $5 p$ phenotype. Newly described patients with duplications in this region will enable more precise limitation of the mentioned region and clarify genotype-phenotype correlations.

\section{Conclusion}

To conclude, this report indicates that the actual state of the complex phenotype observed in our patient is likely due to the influence of both chromosomal aberrations and not primarily due to the deletion, as described previously in patients with a terminal deletion with inverted duplication. Namely, the most prominent phenotypic features noted in our patient, except from the cat-like cry, are results of the chromosome 5p duplication. Also, the patient follow-up will contribute to better understanding of the impact of the $5 p$ deletion on speech delay. Comparison of our patient with new $\mathrm{CdC}$ patients with a cat-like cry will hopefully contribute to narrowing the critical region for this feature, while the described duplication could be conducive to more accurate genotypephenotype correlations in Trisomy $5 p$ in future.

\section{Consent}

Written informed consent was obtained from the patient's parents to take part in the study as well as for publication of the images (including full-face pictures). A copy of the written consent is available for review by the Editorin-Chief of this journal.

\section{Abbreviations}

CdC: Cri-du-chat; MRI: Magnetic resonance imaging; CGH: Comparative genomic hybridization; FISH: Fluorescent in situ hybridisation; BAC: Bacterial artificial chromosome; PCR: Polymerase chain reaction; Mb: Mega base; CHD: Congenital heart defects.

\section{Competing interests}

The authors declare that they have no competing interests.

\section{Authors' contributions}

DK wrote the manuscript and carried out the molecular karyotyping and data analysis; $A B$ and $A B$ performed a clinical analysis of the patient; $A Z$ conducted the cytogenetic analysis; and NKV coordinated the study. All the authors have read and approved the manuscript.

\section{Acknowledgements}

We thank patient's family for the cooperation. Our work was supported by a PhD fellowship for young investigators and the research programme P4-0220, Comparative genomics and genomic biodiversity of the Slovenian Research Agency (ARRS).

\section{Author details}

'Laboratory of Medical Genetics, University Clinical Centre Maribor, Ljubljanska Street 5, 2000 Maribor, Slovenia. ${ }^{2}$ Paediatric Clinics, University Clinical Centre Maribor, Ljubljanska Street 5, 2000 Maribor, Slovenia. ${ }^{3}$ Faculty of Medicine, University of Maribor, Slomškov trg 15, 2000 Maribor, Slovenia.

Received: 18 April 2013 Accepted: 6 February 2014

Published: 11 February 2014

\section{References}

1. Cerruti Mainardi P: Cri du chat syndrome. Orphanet J Rare Dis 2006, 1:33.

2. Church DM, Bengtsson U, Nielsen KV, Wasmuth JJ, Niebuhr E: Molecular definition of deletions of different segments of distal $5 p$ that result in distinct phenotypic features. Am J Hum Genet 1995, 56:1162-1172.

3. Overhauser J, Huang X, Gersh M, Wilson W, McMahon J, Bengtsson U, Rojas K, Meyer M, Wasmuth JJ: Molecular and phenotypic mapping of the short arm of chromosome 5: sublocalization of the critical region for the cri-du-chat syndrome. Hum Mol Genet 1994, 3:247-252.

4. Niebuhr E: The Cri du Chat syndrome: epidemiology, cytogenetics, and clinical features. Hum Genet 1978, 44:227-275.

5. Wu Q, Niebuhr $E$, Yang $H$, Hansen L: Determination of the 'critical region' for cat-like cry of Cri-du-chat syndrome and analysis of candidate genes by quantitative PCR. Eur J Hum Genet 2005, 13:475-485.

6. Zhang X, Snijders A, Segraves R, Zhang X, Niebuhr A, Albertson D, Yang H, Gray J, Niebuhr E, Bolund L, Pinkel D: High-resolution mapping of genotype-phenotype relationships in cri du chat syndrome using array comparative genomic hybridization. Am J Hum Genet 2005, 76:312-326.

7. Cervera M, Sánchez S, Molina B, Alcántara MA, Del Castillo V, Carnevale A, González-del Angel A: Trisomy of the short arm of chromosome 5 due to a de novo inversion and duplication (5)(p15.3 p13.3). Am J Med Genet A 2005, 136A:381-385.

8. Sreekantaiah C, Kronn D, Marinescu RC, Goldin B, Overhauser J: Characterization of a complex chromosomal rearrangement in a patient with a typical catlike cry and no other clinical findings of cri-du-chat syndrome. Am J Med Genet 1999, 86:264-268.

9. Kleczkowska A, Fryns JP, Moerman P, Vandenberghe K, Van den Berghe H: Trisomy of the short arm of chromosome 5: autopsy data in a malformed newborn with inv dup (5) (p13.1-p15.3). Clin Genet 1987, 32:49-56. 
10. Leichtman LG, Werner A, Bass WT, Smith D, Brothman AR: Apparent Opitz BBBG syndrome with a partial duplication of 5p. Am J Med Genet 1991, 40:173-176

11. Lorda-Sánchez I, Urioste M, Villa A, Carrascosa MC, Vázquez MS, Martínez A, Martínez-Frías ML: Proximal partial $5 p$ trisomy resulting from a maternal (19;5) insertion. Am J Med Genet 1997, 68:476-480.

12. Chia NL, Bousfield $L R$, Johnson BH: A case report of a de novo tandem duplication (5p) (p14--pter). Clin Genet 1987, 31:65-69.

13. Wang JC, Coe BP, Lomax B, MacLeod PM, Parslow MI, Schein JE, Lam WL, Eydoux P: Inverted duplication with terminal deletion of $5 p$ and no cat-like cry. Am J Med Genet A 2008, 146A:1173-1179.

14. Vetro A, lasci A, Dal Bello B, Rossi E, Messa J, Montanari L, Cesari S, Zuffardi O: A prenatal case of duplication with terminal deletion of $5 p$ not identified by conventional cytogenetics. Prenat Diagn 2008, 28:1171-1173.

15. Vera-Carbonell A, Bafalliu JA, Guillén-Navarro E, Escalona A, Ballesta-Martínez MJ, Fuster C, Fernández A, López-Expósito I: Characterization of a de novo complex chromosomal rearrangement in a patient with cri-du-chat and trisomy 5p syndromes. Am J Med Genet A 2009, 149A:2513-2521.

16. Mosca AL, Callier P, Faivre L, Laurent N, Rousseau T, Marle N, Payet M, Guy H, Couvreur S, Masurel-Paulet A, Sagot P, Thauvin-Robinet C, Mugneret F: A prenatal case of inverted duplication with terminal deletion of $5 p$ not including the cat-like cry critical region. Am J Med Genet A 2011, 155A:2031-2034.

17. Izzo A, Genesio R, Ronga V, Nocera V, Marullo L, Cicatiello R, Sglavo G, Paladini D, Conti A, Nitsch L: $40 \mathrm{Mb}$ duplication in chromosome band 5 p13.1p15.33 with $800 \mathrm{~kb}$ terminal deletion in a foetus with mild phenotypic features. Eur J Med Genet 2012, 55:140-144.

18. Velagaleti GV, Morgan DL, Tonk VS: Trisomy 5p. A case report and review. Ann Genet 2000, 43:143-145.

19. Gersh M, Goodart SA, Pasztor LM, Harris DJ, Weiss L, Overhauser J: Evidence for a distinct region causing a cat-like cry in patients with $5 p$ deletions. Am J Hum Genet 1995, 56:1404-1410.

20. Mainardi PC, Perfumo C, Cali A, Coucourde G, Pastore G, Cavani S, Zara F, Overhauser J, Pierluigi M, Bricarelli FD: Clinical and molecular characterisation of 80 patients with $5 p$ deletion: genotype-phenotype correlation. J Med Genet 2001, 38:151-158.

21. Avansino JR, Dennis TR, Spallone P, Stock AD, Levin ML: Proximal 5p trisomy resulting from a marker chromosome implicates band $5 \mathrm{p} 13$ in 5p trisomy syndrome. Am J Med Genet 1999, 87:6-11.

22. D'Amato Sizonenko L, Ng D, Oei P, Winship I: Supernumerary marker chromosomes 5: confirmation of a critical region and resultant phenotype. Am J Med Genet 2002, 111:19-26.

23. Loscalzo ML, Becker TA, Sutcliffe M: A patient with an interstitial duplication of chromosome 5p11-p13.3 further confirming a critical region for 5p duplication syndrome. Eur J Med Genet 2008, 51:54-60.

doi:10.1186/1471-2350-15-21

Cite this article as: Krgovic et al:: A coalescence of two syndromes in a girl with terminal deletion and inverted duplication of chromosome 5. BMC Medical Genetics 2014 15:21.

\section{Submit your next manuscript to BioMed Central and take full advantage of:}

- Convenient online submission

- Thorough peer review

- No space constraints or color figure charges

- Immediate publication on acceptance

- Inclusion in PubMed, CAS, Scopus and Google Scholar

- Research which is freely available for redistribution 